\title{
Wear of Fluorapatite Single Crystals: VI. Influence of Multiple-Pass Sliding on Surface Failure
}

\author{
J. M. POWERS, K. C. LUDEMA, and R. G. CRAIG
}

School of Dentistry and College of Engineering, University of Michigan, Ann Arbor, Michigan 48104, USA

The influence of multiple-pass sliding on the surface failure of fuorapatite single crystals was evaluated. The surface and sub. surface damage on the basal plane of fuorapatite was accelerative, rather than additive. Damage was more severe for sliding in opposite directions than for two traversals in the same direction.

One approach to a fundamental study of the wear of a material is to investigate the frictional behavior and surface failure of a simplified system, such as single crystals, under conditions of single-pass sliding. Such an approach has been used to study the influence of sliding direction and environment on the surface failure of fluorapatite single crystals. ${ }^{1,2}$ A useful extension of this singlepass technique would be to make multiple passes, and to compare the results of multiple-pass sliding with the results of singlepass sliding.

The purpose of this study was to evaluate the influence of multiple-pass sliding on the surface failure of the basal plane of fluorapatite single crystals.

\section{Materials and Methods}

A diamond hemisphere (360 micrometers $[\mu \mathrm{m}]$ in diameter) ${ }^{a}$ was slid $^{3}$ across the basal

Based on a dissertation submitted in partial fulfillment of the requirements for the PhD degree in the Horace H. Rackham School of Graduate Studies at the University of Michigan, 1972.

This paper was presented, in part, at the 50 th general session of the IADR in Las Vegas, Nevada, March 1972.

This investigation was supported, in part, by USPHS Training Grant DE-00181 from the National Institute of Dental Research, National Institutes of Health, Bethesda, Md.

Received for publication May 10, 1972.

* Wheel Trueing Tool Company, Detroit, Mich. surface of natural fluorapatite (FAP) single crystals." The failure classification of each scar was determined. 4 Study of the mechanism of failure was made with the aid of a scanning electror microscope (SEM) . ${ }^{c}$

The influence of five types of multiplepass sliding (wear I to wear $V$ ) on the surface failure of the basal plane of FAP was studied as shown in Figure 1. In wear I, we studied the surface failure that resulted when two, one-traversal scars were superimposed exactly on one another in the same sliding direction with the same normal load. To identify the change in failure behavior, the second scar was made for only half the length of the first scar. Fifteen parallel scratches that resulted from sliding a normal load of 10 to $150 \mathrm{gm}$ in increments of 10 gm were made on the basal plane of two FAP crystals (FAP23 and FAP31) in the $x$ sliding direction. All runs were made in air. Areas $a, b$, and $c$, which correspond to a multiple-pass scar, the intersection of multiple-pass scar with a single-pass scar, and a single-pass scar, respectively, then were examined in the SEM.

In wear II, a situation similar to wear I occurred; but a single-pass scar was made, followed by a double-pass scar adjacent to it in the same sliding direction under the same normal load. This condition allowed the wear scars to be twice as long as the scars made under conditions of wear I. In this way, the average failure behavior could be identified more easily. For wear II, only scratches corresponding to normal loads of I0 to $80 \mathrm{gm}$ were examined, since two paral-

\footnotetext{
b Southwest Scientific Company, Hamilton, Mont.

"ISM-U3, Japan Electron Optics Laboratories, Jap.
} 


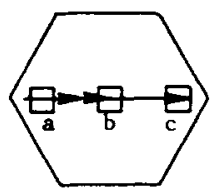

Wear I: Two, one-traversal scars exactly superimposed on one another in the same sliding direction.

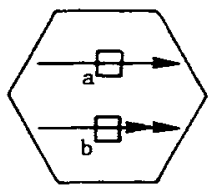

Wear II: A single pass scar followed by a double pass scar adjacent to it in the same sliding direction.

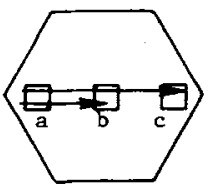

Wear III: Two, one-traversal scars almost superimposed on one another in the same sliding direction.

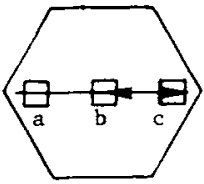

Wear IV: Two, one-traversal scars exactly superimposed on one another but in opposite sliding directions.

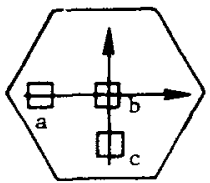

Wear V: One-traversal scars in the $x$ sliding direction crossed with one-traversal scars in the $y$ sliding direction.

Fic 1.-Diagram of experimental procedure; $a, b, c$, areas of observation under the SEM.

lel tracks were required for each load. All runs were made in air with a diamond hemisphere as a slider. Areas $a$ and $b$ were examined in the SEM (Fig 1). Crystals FAP23 and FAP31 were used for studying wear II.

In wear III, we studied the surface failure that resulted when two, one-traversal scars were almost superimposed on one another in the same sliding direction with the same normal load (Fig 1). The remaining experimental procedure described for wear I was used for wear III. Crystals FAP23 and FAP31 were used in this study.

In wear IV, we examined the surface failure resulting when two, one-traversal scars were superimposed exactly on one an- other, but in opposite sliding directions, using the same normal load. The rest of the experimental procedure described for wear $I$ is applicable. Areas $a, b$, and $c$ were observed in the SEM. Crystals FAP22 and FAP30 were used.

In wear $V$, we studied the surface failure that resulted when one-traversal scars in the $x$ sliding direction were crossed with onetraversal scars in the $y$ sliding direction on the basal plane of FAP; 10, 50, and $100 \mathrm{gm}$ normal loads were used (Fig I) for a total of 18 observations. All runs were made in air with a diamond hemisphere as a slider. Areas $a, b$, and $c$ then were examined in the SEM. Crystals FAP2I and FAP42 were used. 


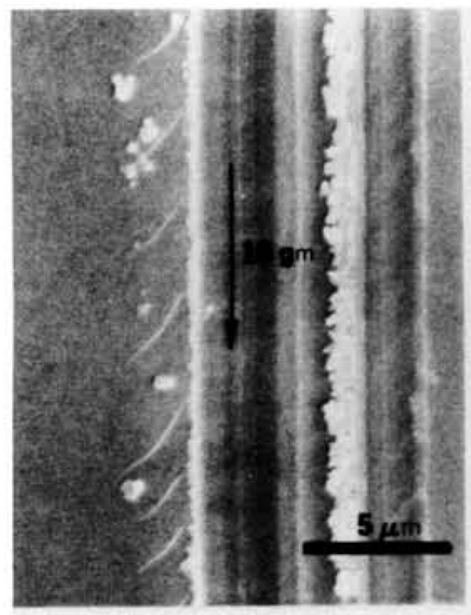

(a) WII-a

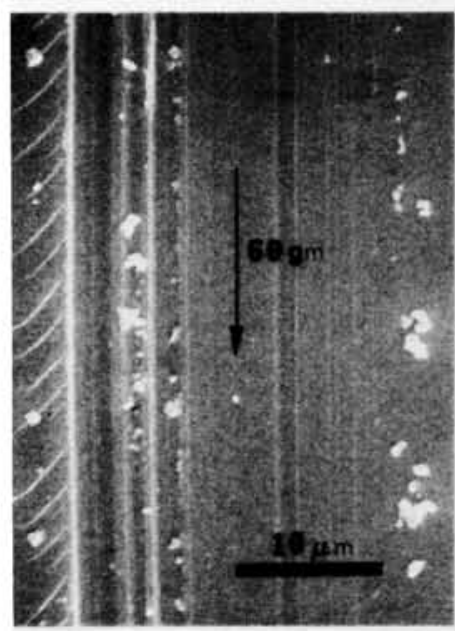

(c) WII-a

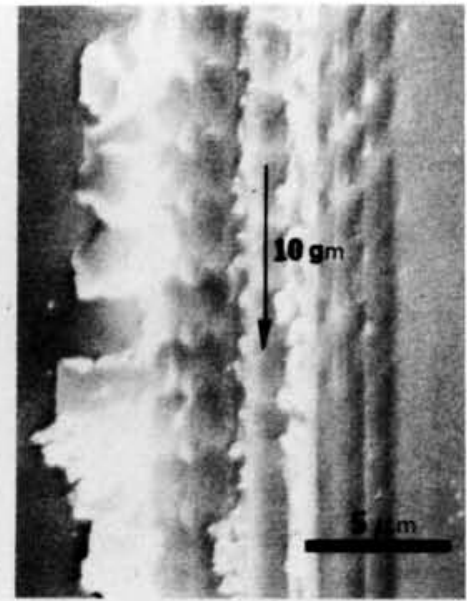

(b) WII-b

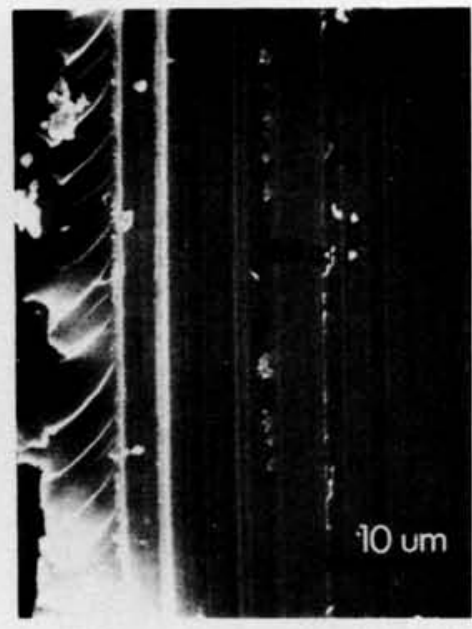

(d) WII-b

FIG 2.-Wear tracks under conditions of wear II.

\section{Results}

Photomicrographs of modes of surface failure as influenced by multiple-pass sliding were obtained. The five types of multiple-pass sliding were coded as wear I (WI) to wear $\mathrm{V}(\mathrm{WV})$. The specific area of the track is indicated by the letters, $a, b$, or $c$. as described in Figure 1. Thus, a photomicrograph that shows the intersection of two perpendicular tracks (area $b$ ) under conditions of wear $\mathrm{V}$ would be coded WV- $b$. The results are based on observations made on two specimens for each of the five types of multiple-pass sliding. Where confusion might occur, the crystal from which the photomicrographs were taken is identified in the figure. The direction of sliding, the normal load used, and a magnification scale are indicated on each figure.

Observations of areas $a, b$, and $c$ for wear I and areas $a$ and $b$ for wear II were similar; therefore. we concluded that either experimental procedure was valid in studying differences in modes of surface failure between 


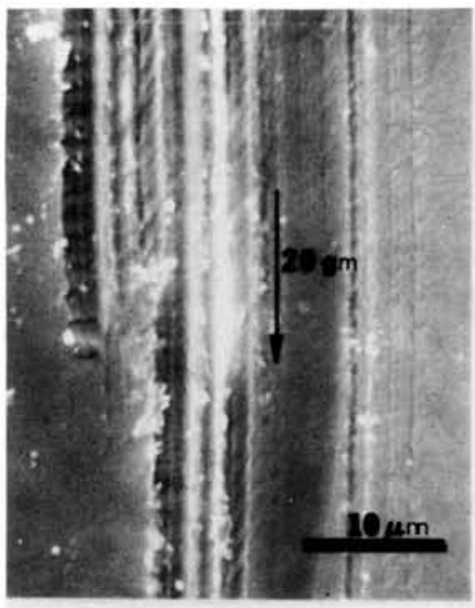

(a) WIII-b

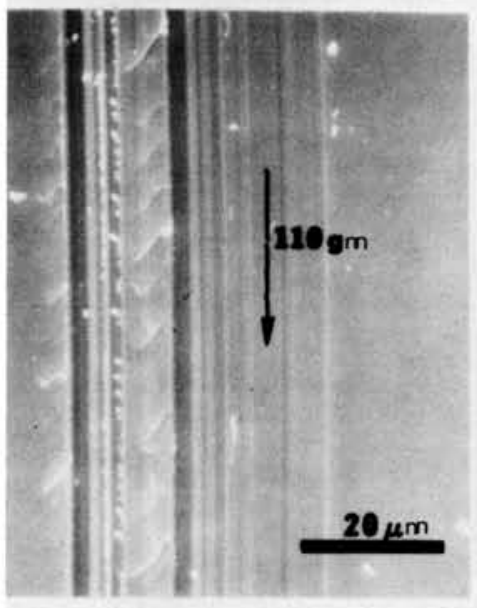

(c) WIII-a

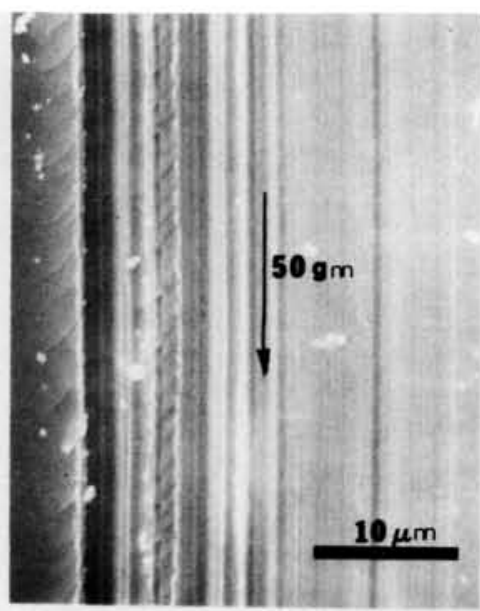

(b) WIII-a

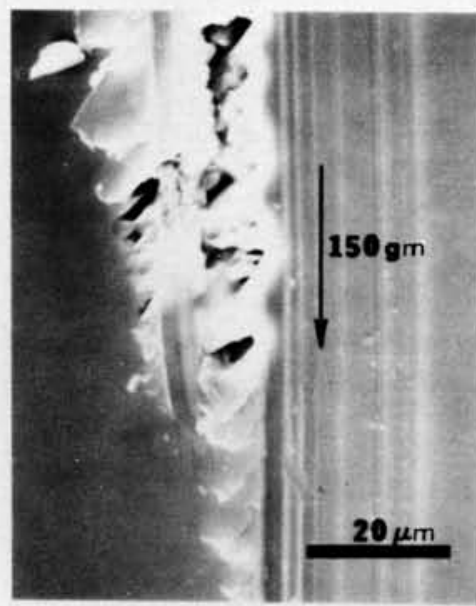

(d) WIII-b

Fig 3.-Wear tracks under conditions of wear III.

single-pass and double-pass traversals.

Scanning electron photomicrographs of wear tracks obtained under conditions of wear II are shown in Figure 2 for normal loads of 10 and $60 \mathrm{gm}$. In (a) d and (b), a comparison was made between a single-pass traversal and a double-pass traversal under normal loads of $10 \mathrm{gm}$. The surface failure in (a) was characteristic of Class 2 failure,

\footnotetext{
"Small letters in parentheses refer to figures and are not to be confused with the small italic letters (not in parentheses) that refer to specific areas of the wear
} track. whereas that in (b) was characteristic of Class 4 failure. $^{4}$ Likewise in (c) and (d), a comparison was made between a singleand a double-pass traversal under normal loads of $60 \mathrm{gm}$. The surface failure in (c) was characteristic of Class 3 failure, whereas that in (d) was characteristic of Class 4 failure. In both of these comparisons, the mode of surface failure was more severe for the double-pass traversal. In addition, we observed that subsurface damage, as indicated by increased reflection of light during optical examination on a metallograph, was more severe for a double-pass traversal than 


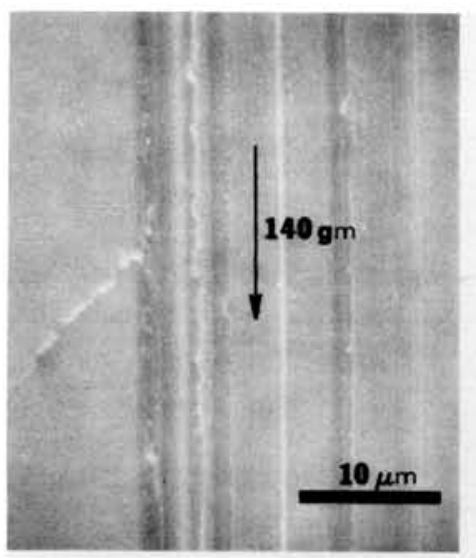

(a) WIV-a, FAP22

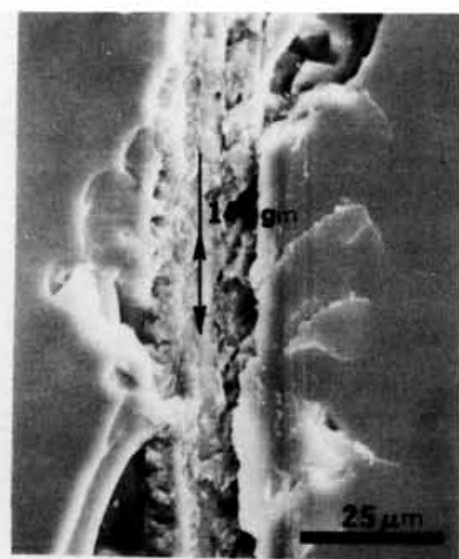

(b) WIV-c, FAP22

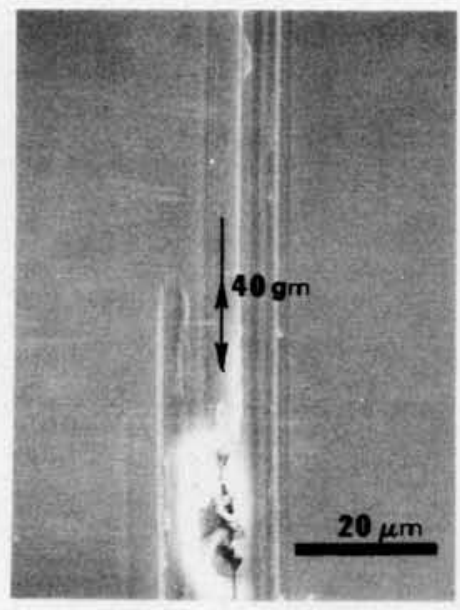

(c) WIV-b, FAP39

Fig 4.-Wear tracks under conditions of wear IV, (a) to (c).

for the single-pass traversal under the same normal load.

Scanning electron photomicrographs of wear tracks obtained under conditions of wear III are shown in Figure 3 for normal loads of 20, 50, 110, and $150 \mathrm{gm}$ Figure 3 . (a) shows area $b$, the intersection between the single- and double-pass traversals, under a normal load of $20 \mathrm{gm}$. No change in the mode of surface failure (Class 1) could be discerned; however, increased subsurface reflection along the length of the double-pass traversal was noted. In (b) and (c) area $a$ under a normal load of $50 \mathrm{gm}$ and 110 gm, respectively. can be seen. Two distinct rows of tensile cracks are apparent; this indicates that no change in the mode of surface failure (Class 3) occurred as a result of the second pass. However, increased subsurface damage was observed in the area swept out by the second pass in both cases. Figure 3, (d), shows area $b$ under a normal load of $150 \mathrm{gm}$. The mode of surface failure in the double-pass area was considerably more severe (Class 5) than that in the single-pass area (Class 4). Once again, the subsurface damage was more severe in the double-pass area.

Figure 4 consists of the scanning electron photomicrographs of wear tracks obtained 


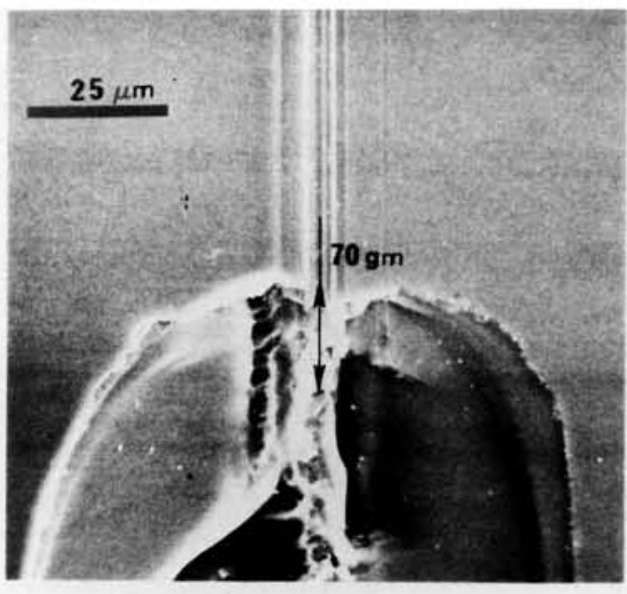

(d) WIV-b, FAP39

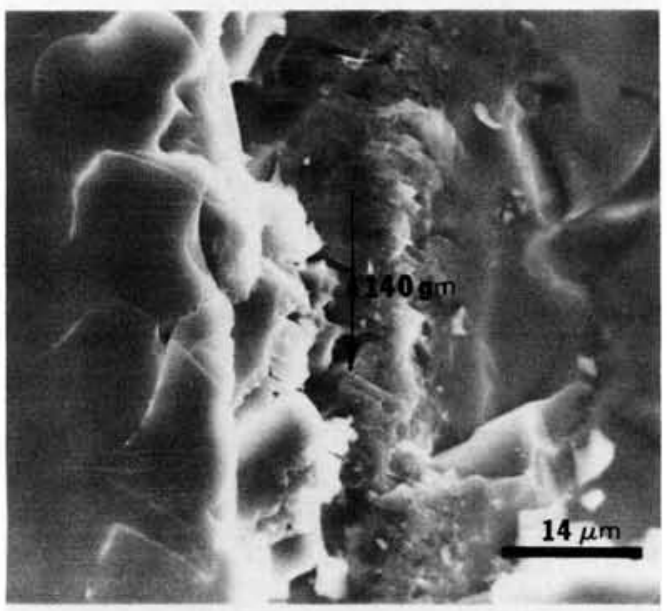

(c) WIV-c, FAP39

Fig 4 (cont).-Wear tracks under conditions of wear IV, (d) and (e).

under conditions of wear IV for FAP22 under a load of $140 \mathrm{gm}$ and for FAP39 under loads of 40,70 , and $140 \mathrm{gm}$. In (a) and (b) a comparison was made between areas $a$ and $c$ of FAP22 under a normal load of $140 \mathrm{gm}$. We observed that the mode of surface failure was considerably more severe with the double pass (area $c$ ) than with the single pass (area $a$ ). In addition, it ap. peared that the center of the wear track in area $c$ underwent considerably more damage than would have been anticipated from similar areas under conditions of wear I,
II, or III. Figure $4,(c)$, shows area $b$ of FAP39 under a load of $40 \mathrm{gm}$. The mode of surface failure (as characterized by damage at the edges of the scars) was Class 1 in the single- and double-pass areas. However, it was clear that the center of the double-pass scar was damaged to an extent not normally associated with Class 1 failure, but not uncommon to the conditions of wear IV. In $(d)$, area $b$ of FAP39 under a load of $70 \mathrm{gm}$ is shown; the transformation in the mode of surface failure was dramatic. Area $a$ was typical of Class 1 failure, whereas area $c$ was characteristic of surface failure similar to that of Class 5 failure. In area $c$, the mode of surface failure appeared to differ from that normally associated with Class 5 failure, in that chevrons and tensile cracks at the edge of the wear scar were not seen; rather, a broad chevron that seemed to have propagated in both directions from the bottom of the wear scar was observed at this load. Figure 4, (e), shows area $c$ of FAP39 under a load of $140 \mathrm{gm}$. This scar in the double-pass area was characterized by damage in the center of the track similar to other scars made under conditions of wear IV. Of particular interest was the observation of tensile cracks aligned almost perpendicular to one another emanating from the edges of the double-pass scar. An example of these perpendicular cracks is shown in the left side of the scar in (e).

Scanning electron photomicrographs of wear tracks obtained under conditions of wear $\mathrm{V}$ are shown in FAP21 and FAP42 under various load combinations in Figure 5. The numerals 1 and 2 at the tip of the arrow indicate the order of sliding. Figure 5 , (a), shows area $b$ of FAP21, where the track of a $10 \mathrm{gm}$ load intersected the track of a $100 \mathrm{gm}$ load. No increase in surface damage appeared to have occurred at this intersection. In (b), area $b$ of FAP42 is shown; the track of a $10 \mathrm{gm}$ load intersected the track of a $50 \mathrm{gm}$ load. It appeared that a chip had formed in the lower right quadrant delineated by the two intersecting scars. In (c), area $b$ of FAP21 is shown; the track of a $50 \mathrm{gm}$ load intersected the track of another $50 \mathrm{gm}$ load. A large chip was observed in the lower left quadrant. Note that track 1 would be classified as a Class 1 failure, whereas track 2 would be classified as a Class 2 failure, al- 


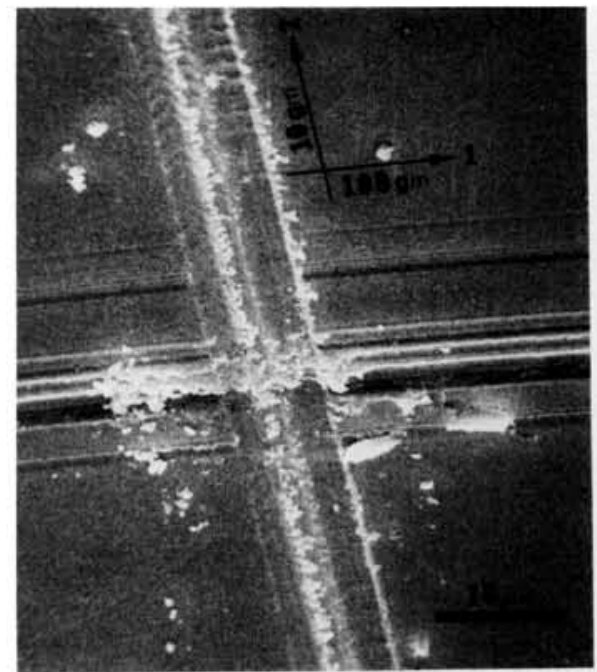

(a) WV-b, PAP21

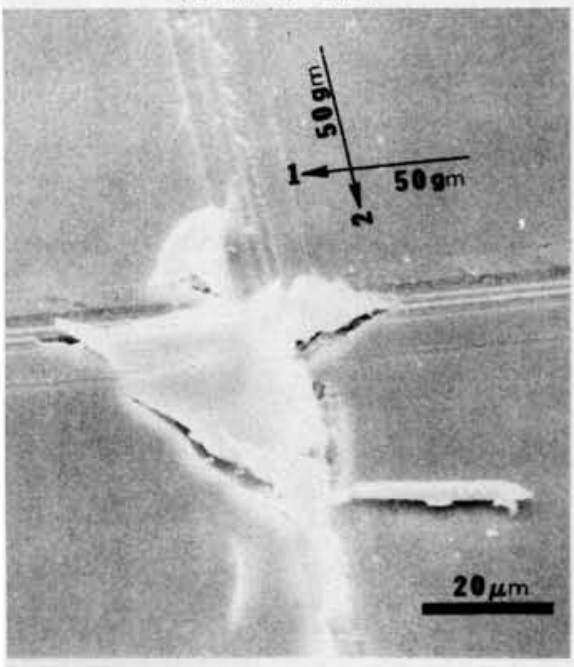

(c) WV-b, FAP21

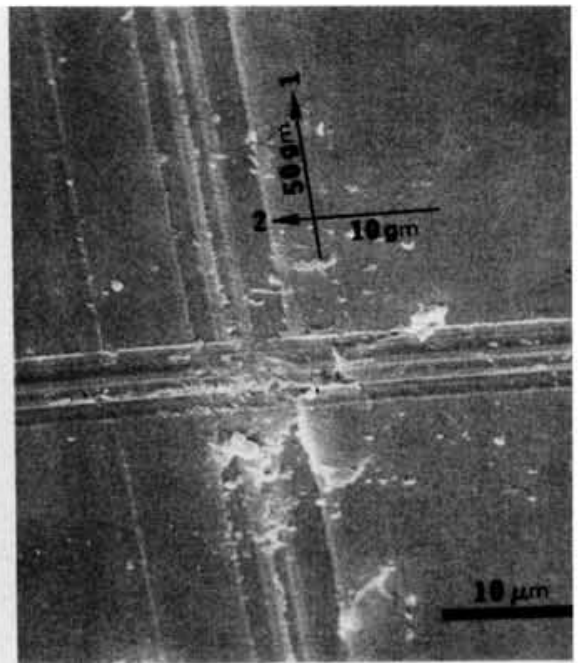

(b) WV-b, FAP42

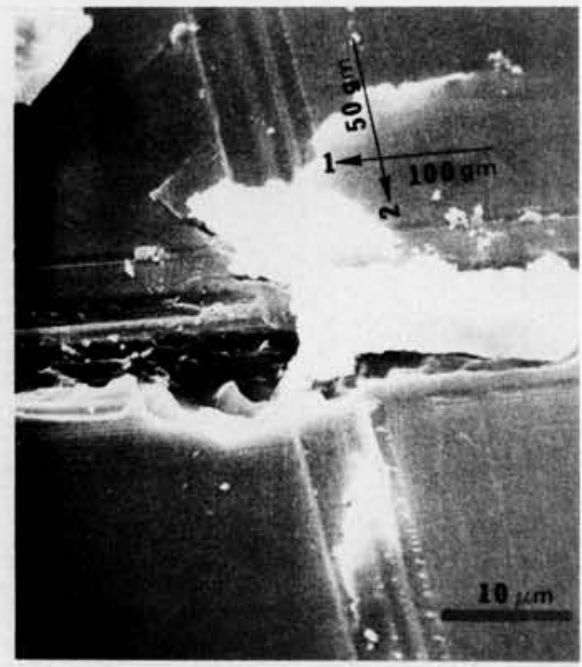

(d) WV-b, $7 \mathrm{AP} 21$

Fig 5.-Wear tracks under conditions of wear V, (a) to (d).

though both were formed under the same normal load. Figure 5, (d), shows area $b$ of FAP21, where the track of a $50 \mathrm{gm}$ load intersected the track of a $100 \mathrm{gm}$ load. The increase in surface damage observed at the intersection of the two scars was made apparent by the large chips still attached to the crystal. In (e), area $b$ of FAP42 is presented; the track of a $50 \mathrm{gm}$ load intersected the track of another $50 \mathrm{gm}$ load. The change in the mode of surface failure at the intersection was dramatic. Figure 5, (f), shows area $b$ of FAP42, where the track of a $50 \mathrm{gm}$ load intersected the track of a 100 gm load. Although track 1 would be classified as a Class 5 failure, it was apparent that additional damage had occurred in the upper and lower right quadrants (immediately beyond the large chevron) as a result of the intersecting scar. 

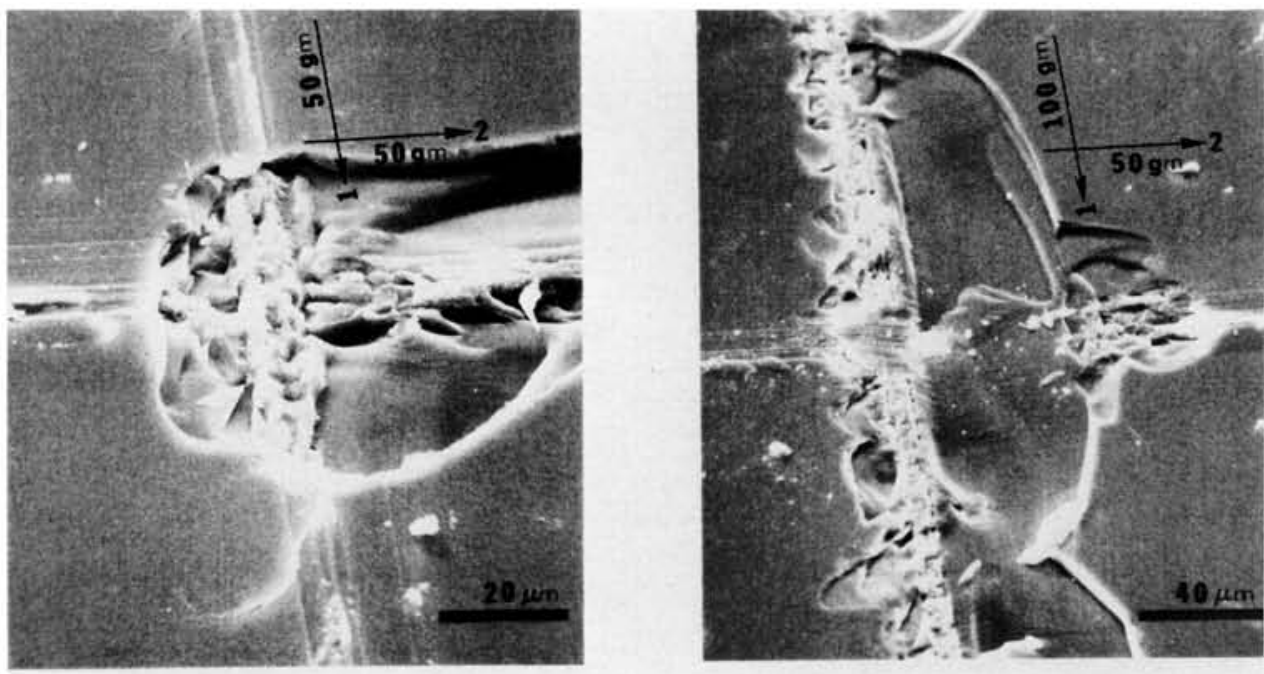

(e) WV-b, FAP42

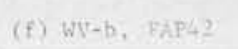

FIG 5 (cont).-Wear track under conditions of wear V, (e) and (f).

\section{Discussion}

Several experiments of limited magnitude were designed to initiate research on the subject of wear caused by multiple-pass sliding and its relationship to wear caused by single-pass sliding. The results support the proposition that the wear of a material under conditions of repeated sliding is more severe than what might have been expected on the basis of single-pass sliding.

The results from study of wear I, II, III, and IV support the hypothesis that surface and subsurface failure on the basal plane of FAP as a result of sliding is accelerative. rather than additive. This is true even when the tracks are not superimposed exactly on one another, wear III. Reversing the direction of sliding was most destructive. The effects of this accelerative damage were most dramatic at loads where tensile cracking, but not chevron formation, occurred on the first pass. The second pass invariably resulted in chevron formation. In wear IV, where the direction of sliding was reversed, failure similar to that observed for sliding in water ${ }^{2}$ under singlepass conditions was observed. These observations are consistent with the theory that the amount of plastic deformation available during sliding on the basal plane is limited. ${ }^{1}$ If the amount of strain available by slip were used during a single pass, then subsequent passes would necessarily cause cracking regardless of the load of these latter passes.

The results of study of wear $\mathrm{V}$ support the aforementioned theory and offer some insight into the interaction of cracks that occur at the intersection of two perpendicular wear scars. Figure 6 indicates the intersection of two hypothetical wear scars. If possible changes in crack orientation as a

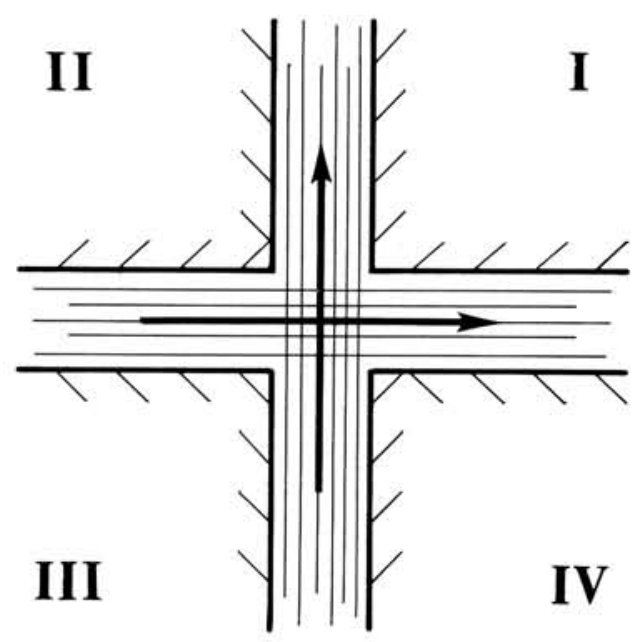

FIG 6.-Model shows intersection of two hypothetical wear scars. 
function of sliding direction are ignored, this model would predict the formation of chips in quadrant III. The damage in quadrants I, II, and IV presumably would not be as severe. Photomicrographs that support this model were presented in Figure 5. (a) and (d).

\section{Conclusions}

The influence of multiple-pass sliding on the surface failure of fluorapatite single crystals was evaluated. Surface and subsurface damage under conditions of multiple-pass sliding was accelerative, rather than additive. Two-pass sliding over the same track. but in opposite directions, was particularly destructive.

\section{References}

1. Powers, J.M.; Ludema, K.C.; and Craig, R.G.: Wear of Fluorapatite Single Crystals: IV. Influence of Sliding Direction on Frictional Behavior and Surface Failure, $J$ Dent Res 52: 1019-1025, 1973.

2. Powers, J.M.; Ludema, K.C.; and Craig, R.G.: Wear of Fluorapatite Single Crystals: V. Influence of Environment on Frictional Behavior and Surface Failure, $J$ Dent Res 52: 1026-1031, 1973.

3. Powers, J.M., and Craig, R.G.: Wear of Fluorapatite Single Crystals. I. A Method for Quantitative Evaluation of Wear, $J$ Dent Res 51: 168-176, 1972.

4. Powers, J.M., and Craig, R.G.: Wear of Fluorapatite Single Crystals. III. Classification of Surface Failure, $J$ Dent Res 51:611$618,1972$. 